\title{
Inclusive education and stereotypes among teachers from mainstream schools
}

\author{
Irina-Cristina Pachița ${ }^{\bullet}$, Alois Gherguț
}

\begin{abstract}
:
Despite the constant efforts to implement an inclusive education system at the level of educational policies and practices, there are nevertheless a number of factors influencing the effectiveness of inclusive education. Teachers, as key actors of education through the lens of their work, are a determining factor in the success of the implementation of inclusive education and the quality of education. The way they relate to students with disabilities has a significant impact on the quality of inclusive education. Beliefs about the importance of inclusion, expectations of inclusive education outcomes and inclusive classroom practices have a higher level of occurrence for teachers with fewer stereotypes. Questioning 90 teachers, it has also been shown that the level of stereotypes is lower for teachers who have experience working with children with disabilities. These results demonstrate that the efficiency and quality of an inclusive approach depend on these psychological constructs of teachers and a good inclusive education starts from the beliefs of each teacher. Also, those teachers who have experience working with students with disabilities tend to have a low level of stereotyping, compared to teachers who do not have this type of experience, so coming into contact and the experience, predominantly positive, with students with disabilities leads to knowledge of the specifics of this area, finding resources in diversity and, ultimately, lowering the level of stereotypes that can lead to exclusion and segregation.
\end{abstract}

Keywords: inclusive education; stereotypes; disabilities; mainstream school.

\section{Introduction}

In a rapidly evolving society, changes and differences are increasingly evident in all areas of life and the field of education is one of the areas that constantly faces these changes and challenges. This development brings to the fore the need to accept human diversity, tolerance and the use of resources from what seems to be different and unknown. It is precisely for this reason that the field of education has had to adapt to these differences and gradually learn to ensure equal opportunities for all people, thus managing to respond to their diverse characteristics and needs in terms of education and training.

\footnotetext{
- MA student, Faculty of Psychology and Educational Sciences "Alexandru Ioan Cuza" University, Iaşi, Romania, E-mail: irinapachita@yahoo.com

- PhD Professor, Faculty of Psychology and Educational Sciences "Alexandru Ioan Cuza" University, Iaşi, Romania, E-mail: alois@uaic.ro
} 
Starting from the right to education and belonging of each individual, the need to develop an education for all has become increasingly pronounced, both in national and international contexts, thus shaping inclusive education (Ghergut, 2013). Since past times, a variety of stereotypes and labels have been associated with people with disabilities. In itself, the language used has changed over time, highlighting certain changes in attitudes and beliefs towards differences and disability. It is precisely the terminology used in this field that brings with it a number of implications in shaping beliefs, attitudes, practices and policies (Winter \& O'Raw, 2010).

\section{Inclusive education}

Building on the fact that the right to education was defined by the 1948 - Universal Declaration of Human Rights as a fundamental right, inclusive education is a result of this basic right of all people to have access to an appropriate form of education and not to be excluded. Inclusion in mainstream education is a philosophy of acceptance and community membership that leads to the structuring of the educational process in such a way that it meets the needs of all students (Gal, Schreur, \& Engel-Yeger, 2010). By referring to special education, inclusive education has been defined as the optimal and complete participation of students in mainstream school educational activities, regardless of the nature of their needs, without the element of segregation in their services (Connor, Gabel, Gallagher, \& Morton, 2008).

In addition to the conceptual definition of inclusive education, we note that this refers to a wide range of strategies, activities and procedures designed to lead to respect for the fundamental right to a qualitative and relevant education. Inclusive education reinforces the idea that education begins from the moment of birth and continues throughout life, encompassing both learning in the family environment, in the community, in formal, nonformal and informal contexts; also seeks to strengthen communities, systems and structures in all cultures and contexts precisely to combat discrimination, celebrate diversity, promote participation and overcome barriers in learning for all people. It is also part of a broader strategy to promote the development of inclusion, with the aim of creating a world governed by peace, tolerance, resource sustainability, social justice and where the needs and rights of every man are met (Stubbs, 2008).

When we talk about the quality of inclusive education, we need to refer both to the physical aspects, both academic, behavioral and social (Wilckzenski, 1992). The success of the implementation of inclusive education depends on the quality and quantity of educational policies, as well as on the change of the educational process, the school as an institution and the school as a system.

Teachers, as key actors in education through the lens of their work, are a determinant of the success of the implementation of inclusive education and the quality of education overall (Ratkovic \& Hebib, 2018). Research shows that there is no standard pattern of inclusive education, which is a dynamic, organic, cultural process that depends on the 
context of implementation. However, in achieving inclusive education it is necessary to understand three basic aspects: fundamental human rights together with the documents and tools developed, the elements behind the development of inclusive education, the origins and influences and concepts, models, strategies and what differentiates inclusive education from other educational paradigms (Ainscow, Booth, \& Dyson, 2006).

\section{Stereotypes}

Stereotypes have been defined as simple "images" of our heads of people or events around us. Lippmann explains that our actions are not based on direct knowledge of the real world, because the real environment is too vast and complex to be directly perceived. To adapt to this situation, the author explains that we are building a series of "images" of the environment (including the people around us) (Lippmann, 1922). Stereotypes have also been defined as beliefs or a set of beliefs about the characteristics, attributes or behaviors of a particular group of people or a category of people. Moreover, they are not only beliefs about groups, but also small theories about how and why certain attributes fit (Schneider, 2004). In other words, stereotypes are cognitive structures that link knowledge to a category of people (Bless, Fiedler, \& Strack, 2004). Although stereotypes usually tend to get negative valence, they are not necessarily negative by nature. Stereotypes about people outside our reference group tend more to be negative than for group members, even when attributes are based on positive things (Hilton \& von Hippel, 1996).

Stereotypes are particularly insidious factors in the formation of students' image by teachers. Teachers who rely on stereotypes in favor of knowledge beyond that risk allowing individual and cultural influences to work to their disadvantage and disadvantage to that generation of students (Cook-Sather \& Reisinger, 2001). There have been researchers who have classified stereotypes as correct or incorrect, referring to their validity (Allport, 1954), the correct value of a stereotype as a set of beliefs about people, idea reinforced by Ehrlich (Ehrlich, 1973).

The way teachers and schools treat students with social requirements has a major impact on their intellectual and emotional development, as well as on their self-esteem. Teachers' expectations can be sources of maintenance of stereotypes, especially for children with special requirements, as teachers can use the true level of children's development and performance as proof of the validity of their stereotypes (Rosenthal \& Jacobson, 1968). When we make social categories in school and attach a label to them, we focus on the characteristics that make that child part of that category. As long as students with disabilities are assigned stereotypes and are described as disabled rather than differently empowered or capable, schools receive an image of individuals unable to make a productive contribution and participate in the school community.

Furthermore, while these issues related to the attribution of stereotypes are also added to additional criticism from teachers who also exhibit stereotypes that influence judgments about the performance of students with special requirements, increase the 
level of rejection by peers and the level of non-help in learning on the part of the student as a result of self-assignment and internalization of the label put by others (Zembylas \& Isenbarger, 2002). Previous research found that the most common mentioned stereotypes on disabled people would be that they have poor social skills, are introverted, communicate poorly, have difficult personalities or behaviors. have poor emotional intelligence. (Wood \& Megan, 2016). Another study concerning able-bodied and disabled students have found that the stereotypes attributed to each of the two categories are totally opposite, the disabled students being called introverted, lazy, unassuming, submissive. (Fichten \& Amsel, 1986). A study that had teachers as participants (Campbell $\&$ Gilmore, 2003) verified the existence of stereotypes for students with Down Syndrome, with teachers demonstrating "extremely happy" and "affectionate" stereotypes.

\section{The present study}

Despite the constant efforts to implement an inclusive education system at the level of educational policies and practices, there are nevertheless a number of factors influencing the effectiveness of inclusive education. This research aims to analyze the relationship between inclusive education and stereotypes of mainstream teachers. Based on the assumption that certain aspects of teachers influence their beliefs about inclusive education, we aim to look at the extent to which stereotypes about students with disabilities are an influence factor for these beliefs.

A secondary objective of this research is also to examine the extent to which stereotypes can be influenced by aspects related to the professional experience of teachers. The aim of this study is to provide relevant conclusions and directions on how stereotypes can influence inclusive education and how these stereotypes can be influenced by certain personal attributes, in order to increase the efficiency of inclusive education in Romania, beyond the inclusive policies and practices described and recommended.

In researching the relationship between stereotypes and inclusive education, we will analyze the latter variable through several constructs, general beliefs about the importance of inclusion, expected inclusion outcomes and inclusive practices used in the classroom. When we refer to general beliefs about the importance of inclusion, we are talking about the belief that the students with disabilities have the right to be educated together with typically developed students and that this is most beneficial option to them. With regard to the expected inclusion outcomes, we are talking about a number of real expectations about the outcomes that inclusive education can have on students and on the class. These expectations lead us to the third dimension, that of inclusive practices used in the classroom, which relate to the adaptations, facilities and changes needed for an inclusive education. Therefore, once realistic expectations are established, classroom practices will be optimally analyzed and applied. 


\section{Hypotheses}

In order to analyze how certain factors influence beliefs about the importance and necessity of implementing inclusive education, this research aimed to verify the following hypotheses:

H1: Teacher stereotypes influence their beliefs about inclusive education

H1.1: Teachers with lower levels of stereotypes have significantly better results in general beliefs about the importance of inclusion.

H1.2 Teachers with lower levels of stereotypes perform significantly better in terms of expected outcomes of inclusive education.

H1.3 Teachers with lower levels of stereotypes perform significantly better in terms of the results of inclusive practices.

H2: Working experience with students with disabilities of teachers influences their stereotypes.

H2.1 Teachers who have experience working with students with disabilities have a lower level of stereotyping than teachers who have no experience working with students with disabilities.

H3: Teachers' years of teaching experience influences their stereotypes

H3.1 Teachers with teaching experience in education between 21 and 40 years of age have a higher level of stereotyping.

\section{Methodology}

\section{Participants}

The research was carried out on a sample of 90 teachers from mainstream education in Romania. The sample contains teachers who teach in all four study cycles (pre-school, primary, secondary, high school). The average age of the participants is 43 years, the minimum age being 22 years and the maximum age is 65 years. Subjects teach in both rural and urban areas, 40 of them (44,44\%) teaching in rural areas and $50(55,55 \%)$ in urban areas. Also, the teaching degree they have differs, having 11 starting teachers, 19 definitive, 52 who have the didactic degree I and 8 who have the teaching degree II. Years of teaching experience is also diverse in this sample, with 52 teaching staff with experience between 1 and 20 years and 38 teachers with experience between 21 and 40 years.

\section{Measures}

Beliefs about inclusive education were measured using the My Thinking About Inclusion Scale (MTAI) questionnaire (Stolber, Gettinger, \& Goetz, 1998). This questionnaire aims to measure beliefs about inclusive education and can be used for the application of both teachers and parents. The questionnaire consists of a total of 28 items, evaluated on a Likert scale from 1 to 5 , where 1 means total disagreement and 5 means 
total agreement. The 28 items are divided into 3 subscales covering 3 areas of inclusive education: general beliefs about the importance of inclusion (12 items), expected inclusion outcomes (11 items) and inclusive practices used in the classroom (5 items). For this study, the instrument has good internal consistency ( $\alpha=0.856$ ).

Stereotypes were measured using the Stereotype and Metastereotype Questionnaire (SMQ) (Barkley, 2015) was built to address the appearance of five constructs of stereotypes described by May and Stone (2010) on students with disabilities, with 28 items in total. The questionnaire was divided into five subscales related to the 5 stereotypes: low intelligence (5 items), impossibility of compensation (5 items), processing deficit ( 6 items), insurmountable condition ( 6 items) and working the system (6 items). A Likert scale was used from 1 to 5 , where 1 means total disagreement and 5 means total agreement. These concepts of stereotypes describe an attribute or characteristic of students with disabilities, or a behavior that researchers have proven in previous studies to be relevant in the construction and emergence of stereotypes. The results show good internal consistency ( $\alpha=0.884)$.

\section{Procedure}

The questionnaires, translated and adapted in advance, were completed by participants in electronic form using the Google Forms tool. Prior to the study, participants were informed of the confidentiality and anonymity of their responses, and asked to give honest answers. Also, prior to completing the questionnaires, the subjects were asked to give the consent to participate in this research.

\section{Results}

\section{Correlation analysis}

Table 1 presents the correlations of the 5 constructs of stereotypes, general beliefs about the importance of inclusion, expected results and classroom practices. Following the calculation of the Pearson correlation coefficient, the following significant correlations were identified: 
Table 1. Table of correlations of the 5 constructs of stereotypes, general beliefs about the importance of inclusion, expected outcomes and classroom practices.

\begin{tabular}{|c|c|c|c|c|c|c|c|c|}
\hline & 1 & 2 & 3 & 4 & 5 & 6 & 7 & 8 \\
\hline \multicolumn{9}{|l|}{ 1.Low intelligence } \\
\hline $\begin{array}{l}\text { 2.Impossibility of } \\
\text { compensation }\end{array}$ &, $470^{* *}$ & & & & & & & \\
\hline 3. Processing deficit &, $716^{* *}$ &, $539 * *$ & & & & & & \\
\hline $\begin{array}{l}\text { 4.Insurmountable } \\
\text { condition }\end{array}$ &, $444^{* *}$ &, $353^{* *}$ &, $438^{* *}$ & & & & & \\
\hline $\begin{array}{l}5 \text {. Working the } \\
\text { system }\end{array}$ &, $509 * *$ &, $214^{*}$ &, $491^{* *}$ &, $416^{* *}$ & & & & \\
\hline $\begin{array}{l}\text { 6. General beliefs } \\
\text { about the } \\
\text { importance of } \\
\text { inclusion }\end{array}$ &,$- 283^{* *}$ &,- 153 &,$- 295^{*}$ &,$- 229 *$ &,$- 295 * *$ & & & \\
\hline $\begin{array}{l}\text { 7. Expected } \\
\text { inclusion outcomes }\end{array}$ &,$- 415^{* *}$ &,- 121 &,$- 378^{* *}$ &,- 151 &,$- 345^{* *}$ &, $640 * *$ & & \\
\hline $\begin{array}{l}\text { 8. Inclusive } \\
\text { practices used in the } \\
\text { classroom }\end{array}$ &,$- 298^{* *}$ &,$- 561^{* *}$ &,$- 268^{*}$ &,$- 397^{* *}$ &,- 137 &, $369 * *$ & ,239* & \\
\hline
\end{tabular}

${ }^{*} p<.05,{ }^{* *} p<.01, \mathrm{~N}=90$

General beliefs on the importance of inclusion correlate positively with expected outcomes of inclusion ( $\mathrm{r}=0.640$ ). The level of occurrence of the low intelligence stereotype positively correlates with the level of the occurrence of the stereotype working the system ( $\mathrm{r}=0.509)$. Low intelligence has a positive correlation with processing deficit $(\mathrm{r}=0.716)$. The impossibility of compensation correlates positively with the processing deficit $(\mathrm{r}=0.539)$. General beliefs about the importance of inclusion are positively correlated with the level of inclusive classroom practices $(r=0.369)$. The stereotype of working the system has a positive correlation with the insurmountable condition $(\mathrm{r}=0.416)$. Processing deficit correlates positively with working the system stereotype $(\mathrm{r}=0.491)$. The insurmountable condition and processing deficit are positively correlated $(\mathrm{r}=0.438)$. The impossibility of compensation correlates positively with the insurmountable condition ( $\mathrm{r}=0.353)$. Low intelligence correlates positively with insurmountable condition $(\mathrm{r}=0.444)$. The impossibility of compensation correlates positively with low intelligence $(r=0.470)$. There is a positive correlation between inclusive classroom practices and expected inclusion outcomes $(r=0.239)$, the same being for the impossibility of compensation and the stereotype of working the system $(\mathrm{r}=0.214)$.

The level of inclusive classroom practices correlates negatively with the impossibility of compensation ( $\mathrm{r}=-0.561)$. Inclusive classroom practices have a negative correlation with the insurmountable condition ( $\mathrm{r}=-0.397)$. The level of expected inclusion outcomes correlates negatively with the stereotype of working the system $(r=-0,345)$. Expected 
Table 3. Statistical results of T-Test

\begin{tabular}{rcccc}
\hline & $\boldsymbol{t}$ & $\boldsymbol{p}$ Level & Experience* $^{*}$ & Mean \\
& Level & & Yes & 1,49 \\
Level of & $-2,528$ & 0,013 & No & 1,82 \\
\hline
\end{tabular}

* Experience working with students with disabilities

results of inclusive education are in a negative correlation with processing deficit ( $\mathrm{r}=-$ 0.378). Low intelligence correlates negatively with expected results of inclusive education $(\mathrm{r}=-\mathrm{0.415})$. The level of inclusive classroom practices correlates negatively with the processing deficit $(\mathrm{r}=-\mathrm{0.268})$. General beliefs about the importance of inclusion correlate negatively with working the system stereotype ( $r=-0.295)$. Inclusive classroom practices are in a negative correlation with low intelligence ( $r=-0.298)$. The level of general beliefs about the importance of inclusion correlates negatively with the insurmountable condition ( $\mathrm{r}=-0.229)$. General beliefs about the importance of inclusion correlate negatively with processing deficit ( $\mathrm{r}=-0.265)$. The level of general beliefs about the importance of inclusion correlates negatively with low intelligence ( $r=-0.283)$.

\section{Hypothesis testing}

The testing of the $\mathrm{H} 1$ hypothesis was carried out by applying the statistical T-Test for independent samples in order to analyze possible differences between subjects who recorded a high level of stereotyping and subjects with a low level of stereotyping. For all three subscales that make up the MTAI instrument - general beliefs about the importance of inclusion, expected inclusion outcomes and inclusive practices used in the classroom the results of the statistical test confirmed the general hypothesis according to the following table:

Table 2. Statistical results of T-Test

\begin{tabular}{|c|c|c|c|c|}
\hline & $t$ Level & $p$ Level & Level of stereotyping & Mean \\
\hline \multirow{2}{*}{$\begin{array}{l}\text { General beliefs about the } \\
\text { importance of inclusion }\end{array}$} & \multirow{2}{*}{3,095} & \multirow{2}{*}{0,003} & High & 38,95 \\
\hline & & & Low & 43,22 \\
\hline \multirow{2}{*}{ Expected inclusion outcomes } & \multirow{2}{*}{3,855} & \multirow{2}{*}{0,000} & High & 36,03 \\
\hline & & & Low & 40,70 \\
\hline \multirow{2}{*}{$\begin{array}{l}\text { Inclusive practices used in the } \\
\text { classroom }\end{array}$} & \multirow{2}{*}{3,157} & \multirow{2}{*}{0,002} & High & 9,83 \\
\hline & & & Low & 11,82 \\
\hline
\end{tabular}

The second hypothesis, H2, was also verified by statistical T-Test for independent samples, with the results indicating that there are significant differences between teachers who have experience working with students with disabilities and those who do not have, in terms of the level of stereotyping. Thus, on the basis of statistical results, the hypothesis formulated by confirms: 
The H3 hypothesis was verified using the statistical T-Test for independent samples, with results indicating that there are differences between the level of stereotypes in teachers that have between 1-20 years of teaching experience and the level of stereotypes for teachers that have between 21-40 years of teaching experience, but these differences have proved not statistically significant, so that the hypothesis is rejected:

Table 4. Statistical results of T-Test

\begin{tabular}{lcccc}
\hline & $\boldsymbol{t}$ Level & $\boldsymbol{p}$ Level & $\begin{array}{c}\text { Teaching experience } \\
\text { (years) }\end{array}$ & Mean \\
\hline \multirow{3}{*}{ Level of stereotyping } & \multirow{2}{*}{$-0,805$} & 0,423 & $1-20$ & 1,52 \\
& & & $21-40$ & 1,61 \\
\hline
\end{tabular}

To analyze which of the five stereotypes recorded a higher level of occurrence, we analyzed the statistical descriptive data in Table 5.

Table 5. Statistical data for the five stereotypes

\begin{tabular}{lllc}
\hline Stereotype & $\mathbf{N}$ & Mean & Std. Dev \\
\hline Low intelligence & 90 & 11,87 & 3,623 \\
Impossibility of compensation & 90 & 18,91 & 3,776 \\
Processing deficit & 90 & 13,32 & 3,625 \\
Insurmountable condition & 90 & 19,86 & 4,476 \\
Working the system & 90 & 12,79 & 4,139 \\
\hline
\end{tabular}

According to these statistical results, in this sample of 90 teachers in mainstream education, the highest level of occurrence was the stereotypical insurmountable condition $(\mathrm{M}=19.86)$, followed by the impossibility of compensation $(\mathrm{M}=18.91)$. The least recorded stereotype was low intelligence $(\mathrm{M}=11.87)$. The results thus show us the increased tendency of teachers in education to consider that the disability of pupils is an insurmountable condition and that they are unable to compensate. At the same time, this data shows a low tendency to assign students with disabilities the label of low intelligence.

\section{Discussions}

This study looked at the relationship between teachers' beliefs on inclusive education and the stereotypes they present about students with disabilities, and investigated how certain factors can influence beliefs about the importance and necessity of implementing inclusive education, with stereotypes being analyzed in this paper. 
The mean of general beliefs on the importance of inclusion for subjects with a high level of stereotyping had a lower result (38.95) compared to subjects with a low level of low levels of stereotypes (43.22), which shows that those teachers with a low level of stereotypes report a higher level of beliefs about the importance of inclusion than those with a high level of stereotypes. From a psychological point of view, teachers with a low level of stereotypes towards students with disabilities tend to have a greater openness to inclusive education and to understand the importance of practicing it, not limited by stereotypes in shaping positive beliefs about inclusion. With a high level of stereotypes, teachers in this category will have limitations in believing that inclusive education is important, thereby affecting its implementation to high quality standards. The fact that they present stereotypes about students with disabilities will not allow them to see beyond these constructs to explore the resources and potential of these students. Studies on teachers' beliefs show that they often manage to overcome stereotypes and change their beliefs about inclusion, despite their training in this field, but manage to do so through their actual experience working with students with disabilities in an inclusive context (Olson \& Bruner, 1996).

Scores on expected inclusion outcomes in subjects with lower stereotypes (40.70) are higher than for subjects with a high level of stereotyping (36.03), which means that those teachers with a lower level of stereotypes have a higher level of expectation when it comes to outcomes of inclusive education than for teachers with a higher level of stereotypes. From a psychological point of view, teachers who report a low level of stereotypes tend to have higher expectations about the possible results of inclusion, precisely in view of the fact that there are no strong stereotypes that could overshadow the achievement of those results. For teachers with high levels of stereotypes, they will have difficulty seeing beyond them, in order to set a number of expectations and objectives for the results of inclusive education. Teachers who report a low level of expectations and a high level of stereotypes cannot see beyond the labels assigned to children with disabilities, without a clear horizon in terms of the results that inclusive education could have. At the same time, based on Olson and Bruner's (1996) idea that each teacher creates his or her own pedagogy based on how children learn and the results they expect from the instructional-educational process (Olson \& Bruner, 1996), pedagogy based on a high level of stereotypes about the results of inclusive education will be significantly affected by them, with low expectations that keep the teacher in an area of simple idea of access to education in terms of inclusive education, without a high level of expectations for the results of inclusion. (Lieber, et al., 1998)

The mean for inclusive classroom practices for subjects with low levels of stereotypes (11.82) is significantly higher than the average for high-level stereotypes (9.38), meaning that those teachers with a low level of stereotypes are significantly higher in terms of inclusive classroom practices than those with high levels of stereotypes. From a psychological perspective, teacher stereotypes affect inclusive education and beliefs about the need for inclusive classroom practices, thereby affecting 
the implementation of inclusion in school by these teachers. Studies show that those teachers who have had positive classroom experiences with students with disabilities tend to have a lower level of stereotyping than the original one, implicitly leading to an increase in inclusive classroom practices (Eiserman, Shisler, \& Healey, 1995). At the same time, the literature highlights that the objectives of a teacher determine a number of expectations, expectations which in the case of students with disabilities are largely determined by the stereotypes that he has about them. These stereotype-based expectations also lead to fluctuations in the level of inclusive practices in the classroom, depending on the level and nature of stereotypes conveyed by the teacher (Schommer, 1994).

The result of the level of stereotypes for teachers with experience working with students with disabilities is lower (1.49) than for teachers who do not have experience working with students with disabilities. This result shows us that those teachers who have experience working with students with disabilities tend to have a low level of stereotypes compared to teachers who do not have this type of experience. Psychologically, coming into contact with a student with disabilities and experiencing how to work with them, including recording their progress, the attitude towards these students becomes more positive and the stereotypes about them start to be deconstructed. On the other hand, teachers who do not have experience working with students with disabilities manifest these stereotypes as a consequence of the lack of knowledge of this field and the lack of information on the specifics of these students. Previous studies have shown that contact and experience working with students with disabilities are in a negative correlation with the level of teacher stereotypes, their level decreasing as teachers have more positive experiences with students with disabilities (Aksamit, Morris, \& Leuenberger, 1987). Zaromatidis demonstrated that there is a significant link between working experience with students with disabilities and the level of stereotyping only in certain cultures, in other cultures this link being insignificant (Zaromatidis, Papadaki, \& Alissa, 1999). Villa, Thousand, Meyers and Nevin argue that practical experience working with students with disabilities and practicing inclusive education develops teachers' skills, fostering positive beliefs about them and reducing the level of stereotyping (Villa, Thousand, Meyers, \& Nevin, 1996).

The results obtained on the level of stereotyping in teachers with teaching experience between 1-20 years are lower (1.52) than for teachers with teaching experience in between 21-40 years (1.61), but this difference is not statistically significant. Psychologically speaking, not confirming this hypothesis is a controversial result. On the one hand, more years of teaching experience lead to higher exposure of teachers to possible inclusive classes containing students with disabilities, their experience having an important influence on stereotypes. In the context of working with students with disabilities for a longer period of time, but not applying inclusive practices, work experience can be classified as negative, and this leads to an increase in the level of stereotypes. Buysse \& Bailey discovers that teachers more years of teaching experience 
in the field felt less comfortable when working with students with disabilities than teachers with less experience in the field (Buysse \& Bailey, 1993).

\section{Conclusion}

Despite its limitations, this study draws a number of relevant conclusions in the knowledge of issues that can influence effective inclusion and in the implementation of inclusive and positive education by teachers as key actors. The results of the research highlighted that those teachers with a low level of stereotypes report a higher level of beliefs about the importance of inclusion, expectations when it comes to the outcomes of inclusive education and a higher level of approach to inclusive practices in the classroom than those with a higher level of stereotypes. Also, those teachers who have experience in working with students with disabilities tend to have a low level of stereotyping, compared to teachers who do not have this type of experience, so coming into contact and the experience, predominantly positive, with students with disabilities leads to knowledge of the specifics of this area, finding resources in diversity and, ultimately, lowering the level of stereotypes that can lead to exclusion and segregation. At the same time, a fair and effective approach to inclusive education develops teachers' skills, fostering positive beliefs about students with disabilities. Another conclusion of this study is that there are no significant differences in the level of stereotypes between teachers with different levels of years of teaching experience. In this regard, studies show that more years of teaching experience lead to higher exposure of teachers to possible inclusive classes containing students with disabilities, their experience valence having an important influence on stereotypes. In the context of working with students with disabilities for a longer period of time, but by not performing inclusive practices, work experience can be classified as negative, and this leads to an increase in the level of stereotypes

This study provides significant information regarding the influence of stereotypes on inclusive education and it is believed that teachers should take these issues into account in educational practice, in particular with a view to promoting quality inclusive education. The results of this study are a good starting point for an insight into the influence of stereotypes in pedagogical practice and a milestone in designing and implementing a plan to increase inclusion in schools.

\section{References}

Ainscow, M., Booth, T., \& Dyson, A. (2006). Improving Schools, Developing Inclusion. Oxon: Routledge. DOI: $10.4324 / 9780203967157$

Aksamit, D., Morris, M., \& Leuenberger, J. (1987). Preparation of student services professionals and faculty for serving learning-disabled college students. Journal of College Student Personnel, 53-59. https://psycnet.apa.org/record/1988-15404-001 
Allport, G. W. (1954). The nature of prejudice. Malden: Addison-Wesley. DOI: 10.1086/221739

Barkley, C. A. (2015). Learning Disabilities: Assessing Stereotypes, Metastereotypes, and Stigma $\begin{array}{lllll}\text { Consciousness . University Honors Program } & \text { Theses, }\end{array}$ https://digitalcommons.georgiasouthern.edu/honors-theses/122

Bless, H., Fiedler, K., \& Strack, F. (2004). Social Cognition: How Individuals Construct Social Reality. Hove, UK: Psychology Press https://b-ok.global/book/3430510/a91e77

Buysse, V., \& Bailey, D. J. (1993). Behavioral and Developmental Outcomes in Young Children with Disabilities in Integrated and Segregated Settings: A Review of Comparative Studies. The Journal of Special Education, 434-461. DOI:10.1177/002246699302600407

Campbell, J., \& Gilmore, L. (2003). Changing student teachers' attitudes towards disability and inclusion. Journal of Intellectual \& Developmental Disability, 369-379. DOI:10.1080/13668250310001616407

Connor, D. J., Gabel, S. L., Gallagher, D. J., \& Morton, M. (2008). Disability studies and inclusive education - implications for theory, research and practice. International Journal of Inclusive Education, 441457. DOI: $10.1080 / 13603110802377482$

Cook-Sather, A., \& Reisinger, O. (2001). Seeing the Students behind the Stereotypes: The Perspective of Three Preservice Teachers. The Teacher Educator 37, no. 2, 91-99. DOI: 10.1080/08878730109555284

Ehrlich, H. J. (1973). The social psychology of prejudice: A systematic theoretical review and propositional inventory of the American social psychological study of prejudice. New York : John Wiley \& Sons. DOI: $10.1086 / 226057$

Eiserman, W. D., Shisler, L., \& Healey, S. (1995). A Community Assessment of Preschool Providers' Attitudes Toward Inclusion. Journal of Early Intervention, 149-167. DOI: $10.1177 / 105381519501900208$

Fichten, C. S., \& Amsel, R. (1986). Trait Attributions About College Students With a Physical Disability: Circumplex Analyses and Methodological Issues. Journal of Applied Social Psychology, 410-427. DOI: 10.1111/j.1559- $\quad$ 1816.1986.tb01149.x

Gal, E., Schreur, N., \& Engel-Yeger, B. (2010). Inclusion of children with disabilities: Teachers attitudes and requirements for enviromental accomodation. International Journal of Special Education, 8999. https://files.eric.ed.gov/fulltext/EJ890588.pdf

Gherguț, A. (2013). Synthesis of Special Psychopedagogy. Guide to competitions and exams for obtaining teaching degrees. Bucharest: Polirom.

Hilton, J. L., \& von Hippel, W. (1996). Stereotypes. Annual Review of Psychology. 237-271. DOI: 10.1146/annurev.psych.47.1.237

Lieber, J., Capell, K., Sandall, S. R., Wolfberg, P., Horn, E., \& Beckman, P. (1998). Inclusive preschool programs: Teachers' beliefs and practices. Early Childhood Reseach Quarterly, 87-105. DOI: 10.1016/S0885-2006(99)80027-1

Lippmann, W. (1922). Public opinion. Oxford: Harcourt Brace.

Olson, D. R., \& Bruner, J. S. (1996). Folk Psychology and Folk Pedagogy. In D. R. Olson, \& N. Torrance, Handbook of human development in education: New models of learning, teaching and schooling (pp. 9-27). Oxford: UK: Blackwell. DOI: 10.5860/choice.34-2877

Ratkovic, M. S., \& Hebib, E. (2018). Inclusive Education as a Framework for Changes in Teachers Work. Teaching Innovations, 20-36. DOI:10.5937/INOVACIJE1803020R

Rosenthal, R., \& Jacobson, L. (1968). Pygmalion in the classroom: teacher expectation and pupils' intellectual development. New York: Rinehart and Winston.

Schneider, D. J. (2004). The Psychology of Stereotyping. New York \& London: The Guilford Press.

Schommer, M. (1994). An emerging conceptualization of epistemological beliefs and their role in learning. In R. Garner, \& P. A. Alexander, Beliefs about text and about text instruction (pp. 25-55). Hillsdale: NJ: Lawrence Erlbaum. DOI: 10.4324/9780203812068 
Stolber, K. C., Gettinger, M., \& Goetz, D. (1998). Exploring Factors Influencing Parents' and Early Childhood Practitioners" Beliefs about Inclusion . Early Chikllto Research Quaderly, 13, No. 1, 107 124. DOI:10.1016/S0885-2006(99)80028-3

Stubbs, S. (2008). Inclusive Education. Where there are few resources. Oslo: The Atlas Alliance.

Unesco. (1994). Salamanca Declaration and directions of action in the field of special education. World Conference on Special Education: Access and Quality. Salamanca. Spain (edited in the Romanian by UNICEF Special Representation in Romania, 1995).: Salamanca.

Villa, R. A., Thousand, J. S., Meyers, H., \& Nevin, A. (1996). Teacher and Administrator Perceptions of Heterogeneous Education. Exceptional Children, 29-45. ED509930

Wilckzenski, F. (1992). Measuring Attitudes Toward Inclusive Education. Psychology in the Schools, 306312. DOI: 10.1002/1520-6807(199210)29:4\%3C306::AID-PITS2310290403\%3E3.0.CO;2-1

Winter, E., \& O'Raw, P. (2010). Literature Review of the Principles and Practices relating to Inclusive Education for Children with Special Educational Needs. The National Council for Special Education .

Wood, C., \& Megan, F. (2016). Students' Stereotypes of Autism. Journal of Educational Issues, 131-140. DOI: $10.5296 /$ jei.v2i2.9975

Zaromatidis, K., Papadaki, A., \& Alissa, G. (1999). A Cross-Cultural Comparison of Attitudes toward Persons with Disabilities: Greeks and Greek-Americans. Psychological Reports, 1189-1196. DOI: 10.2466/pr0.1999.84.3c.1189.

Zembylas, M., \& Isenbarger, L. (2002). Teaching Science to Students with Learning Disabilities: Subverting the Myths of Labeling Through Teachers' Caring and Enthusiasm. Kluwer Academic Publishers. DOI:10.1023/A:1015050706407 